\title{
ENTRE O LÓCUS DE ENUNCIAÇÃO E O LUGAR DE FALA: MARCAR O NÃO- MARCADO E TRAZER O CORPO DE VOLTA NA LINGUAGEM
}

\author{
BETWEEN THE LOCUS OF ENUNCIATION AND THE LOCUS OF SPEECH: MARKING \\ THE UNMARKED AND BRINGING OUR BODIES BACK IN LANGUAGE
}

\section{Gabriel Nascimento*}

\section{RESUMO}

Lócus de enunciação e lugar de fala parecem conceitos primos, mas são produtos de tendências de pensamento distintas, como é o caso dos estudos subalternos (SPIVAK, 1987), a Teoria Racial Crítica (LADSON-BILLINGS e TATE, 1995), os estudos de feministas negras norte-americanas (DAVIS, 1983; CRENSHAW, 1989; HILL COLLINS, 1990), os estudos chicanos (ANZALDUA, 1987), decoloniais (MIGNOLO, 2000), entre outros. Neste trabalho vamos navegar entre os sentidos de lócus de enunciação (MIGNOLO, 2000) e lugar de fala (RIBEIRO, 2017) para compreender como a linguagem constrói a racialização e naturaliza marcado e não-marcado por meio dela. Para isso, vou examinar ambos os conceitos, lugar de fala e lócus de enunciação, a partir de suas delimitações históricas, as similaridades e diferenças entre si, bem como pontos de encontro teórico. Para finalizar, vou propor dispositivos como trazer o corpo de volta, roubado pela colonialidade, e marcar o não-marcado, como forma de ligar o lugar de fala ao lócus de enunciação.

Palavras-chave: lugar de fala; lócus de enunciação; língua (gem).

\section{ABSTRACT}

Locus of enunciation and locus of speech seem to be similar concepts, but they result from different theoretical trends.It is the case of subaltern studies (SPIVAK, 1987), Critical Racial Theory (LADSON-BILLINGS and TATE, 1995), North American black feminism (DAVIS, 1983; CRENSHAW, 1989; HILL COLLINS, 1990), Chicano studies (ANZALDUA, 1987), decolonial studies (MIGNOLO, 2000), among others. In this work we will navigate between the meanings of locus of enunciation (MIGNOLO, 2000) and locus of speech (RIBEIRO, 2017) to understand how language builds racialization and naturalizes marked and unmarked personhood. In doing this, I will examine both concepts, locus of speech and locus of enunciation, on following their historical boundaries, like their similarities and differences, as well as a theoretical point of encounter they have in common. Finally, I will advocate for bringing our body back stolen by coloniality, and marking the unmarked, as a way of connecting the locus of speech to the locus of enunciation.

Keywords: locus of speech; locus of enunciation; language.

As teorias sobre Lugar de fala ${ }^{1}$ e Lócus de enunciação nem sempre são convergentes. Enquanto Lugar de fala passou a ser cada vez mais explorado publicamente no Brasil a partir de Ribeiro (2017), Lócus de enunciação tem uma origem mais complexa e remota.

Enunciação é um conceito que vem sendo discutido desde o trabalho de Benveniste (1976) em sua tentativa de teorizar os sujeitos da enunciação. Para o autor, cada enunciação é inédita e irrepetível. Assim, cada enunciado oriundo de uma dada enunciação é novo, em que um "eu" implica com quem se fala, que está marcado, ainda que implicitamente, na língua. O termo lócus de enunciação, no entanto, vem sendo usado a partir da leitura que Mignolo (2000) faz do trabalho da intelectual mestiça chicana Glória Anzaldúa, ao teorizar o seu chamado pensar fronteiriço.

Lugar de fala vem sendo usado no Brasil para reunir dois fenômenos observados no trabalho de Ribeiro (2017), que traz consigo as vozes do feminismo negro norte-americano, do feminismo branco tradicional ${ }^{2}$ e dos estudos subalternos ${ }^{3}$. Trata-se, assim, da experiência vivida por mulheres negras e teorizadas por elas próprias, sem o uso de intérpretes, e da condição dessas mulheres em serem construídas como o "outro do outro". Parecem dois fenômenos similares, mas são interdependentes por natureza. São interdependentes porque um fenômeno não precisa do outro para existir e porque um condiciona a existência do outro. O lugar de fala cumpriria, portanto, um lugar de "sotaque", que reúne, no caso do Brasil, as experiências vividas, que vêm reconhecidas no trabalho dos estudos decoloniais como lócus de enunciação, sempre a partir do feminismo negro, e do direito de fala de mulheres negras em poderem se fazer representar sem intérpretes.

* Universidade Federal do Sul da Bahia (UFSB), Itabuna, BA, Brasil. gabriel@ufsb.edu.br. Orcid: http://orcid.org/0000-0002-7695-9264

1. Durante todo o texto eu decidi colocar negrito em termos que estou examinando o tempo inteiro e que estão assim grafados por serem os objetos de análise.

2. O feminismo branco tradicional é aquele cujas teorias são suscitadas, principalmente, a partir da obra de Simone de Beauvoir

3. Tendo originado no Reino Unido, a maior influência para este texto no que diz respeito aos estudos subalternos é a obra de Gayatri Spivak. 
"Sotaque" é um termo muito apropriado para falar desse encontro de teorias distintas. Os dicionários disponíveis, como é o caso do Houaiss, avisam que esse termo é de origem obscura justamente para delimitar a dificuldade de dizer o que é um sotaque. Muito provavelmente, sotaque reúne aspectos segmentais e suprassegmentais, bem como gestos e corporeidade dos sujeitos em fala, que têm nomes distintos em outros países. O caso de lugar de fala como teoria que traz consigo a experiência vivida para dentro de sua marca expõe um "sotaque" que carrega também o lócus de enunciação. Se "a dimensão sotaque refere-se à perceção (sic) do ouvinte relativamente ao grau de sotaque do falante, ou seja, quão próximo ou distante o sotaque é relativamente à pronúncia nativa" (RATO et aliae, 2015, p.301, 302), como defendem essas autoras portuguesas, então a metáfora disponível de "sotaque" para compreendemos o papel de lugar de fala carece de melhor entendimento. O principal deles é, tal qual o "sotaque", o exame de suas unidades, isto é, daquilo que compõe o que se chama de lugar de fala.

Neste texto vamos tratar dessas duas teorizações para recuperar a importância do lócus de enunciação no entendimento do lugar de fala. Para isso, vamos partir de suas delimitações históricas, baseadas em seus recortes teóricos de fundação, para afirmar suas similaridades, diferenças e pontos de encontro em sua relação de interdependência.

Por último, tal como Mignolo (2000) fez, ao se inspirar em Glória Anzaldúa para apresentar o seu pensar fronteiriço, vamos propor duas categorizações para lócus de enunciação e sua forma de contribuir para o lugar de fala que são o marcar o não-marcado (Menezes de Souza, 2018) e trazer o corpo de volta (De Souza, 2019) de forma a compreender os limites e a importância da representação para esse debate.

A delimitação de ambos os conceitos sempre pode servir a vendavais teóricos aqui e acolá. É que tanto uma teoria quanto a outra tem limites que a própria convivência teórica formula ao construir seus objetos de arqueologia do saber (FOUCAULT, 2009), quando, ao se escolher trabalhar com um dado objeto de saber e construção do conhecimento, se exclui os demais.

Lugar de fala é um conceito oriundo de teorias do feminismo negro norte-americano, do feminismo branco e dos estudos subalternos. Nesse tripé teórico está em voga a diferença de gênero como ancorada pelo cisheteropatriarcado no ocidente ${ }^{4}$ e suas implicações para a posição dos chamados subalternos e, sobretudo, para as subalternas negras. Ribeiro (2017), no entanto, escolhe recorrer, antes mesmo de partir para uma definição de seu termo-chave, a exemplos oriundos das próprias feministas negras. Recuperando a voz antirracista de Sojourner Truth, relembra a experiência vivida daquela abolicionista afro-americana o fato de muitas vezes ela não ser vista como uma mulher nem pelos seus pares homens negros e nem pelas mulheres brancas. Pesa nessa experiência vivida, indo na contramão do mote metodológico utilizado por Fanon (2008) ao contrapor a mulher de cor e o branco, a relação de não reconhecimento das mulheres negras também por seus pares homens negros. Como elucida a autora, em franca e necessária provocação:

Reconhecer o status de mulheres brancas e homens negros como oscilante nos possibilita enxergar as especificidades desses grupos e romper com a invisibilidade da realidade das mulheres negras. Por exemplo, ainda é muito comum a gente ouvir a seguinte afirmação: "mulheres ganham $30 \%$ a menos do que homens no Brasil", quando a discussão é desigualdade salarial. Essa afirmação está incorreta? Logicamente, não, mas sim do ponto de vista ético. Explico: mulheres brancas ganham 30\% a menos do que homens brancos. Homens negros ganham menos do que mulheres brancas e mulheres negras ganham menos do que todos (RIBEIRO, 2017, p. 23).

Ou seja, apesar da autora começar seu texto perspectivando a experiência vivida de feministas negras, o que poderia ser rasamente compreendido aqui como uma forma de lócus de enunciação dessas vozes, o que ela quer é apresentar o argumento advindo da teoria sobre interseccionalidade (CRENSHAW, 1989), de que mulheres negras se encontram sempre mais minorizadas do que seus pares homens negros e mulheres brancas. Nesse caso, as teorias de Linda Alcoff e Simone de Beauvoir servem ao seu texto como reflexões de que há opressões de gênero, mas a categoria mulher não pode ser generalizada. Além disso, se faz uso das teorias antirracistas de Angela Davis, Giovana Xavier e Grada Kilomba para refletir que os homens negros são também parte do funcionamento dessa opressão. Nos dois casos, a autora desiste de problematizar melhor a experiência vivida dos feminismos brancos, que universalizam

4. O cis-heteropatriarcado é a instituição patriarcal e heteronormativa que rege os valores de gênero e sexualidade no mundo ocidental. É, por natureza, uma construção branca. 
o gênero, para propor, em seu feminist standpoint, a categoria de mulher negra como o outro do outro, oscilando sempre em apresentar com maior profundidade o lócus de enunciação desse outro primeiro, seja ele homem negro ou mulher. Fanon (2008), também explorando a experiência vivida de ser negro na diáspora africana, problematiza essa noção de outro ao criticar os próprios movimentos antirracistas:

O negro em seu país, em pleno século XX, ignora o momento em que sua inferioridade passa pelo crivo do outro... Sem nenhuma dúvida, chegamos a discutir o problema negro com amigos ou, mais raramente, com negros americanos. Juntos protestamos e afirmamos a igualdade dos homens diante do mundo. Havia também nas Antilhas este pequeno hiato entre a békaille, a mulatada e a negrada. Naquela época nos contentávamos em compreender intelectualmente essas divergências. Na verdade, isso não era muito dramático. Mas depois...

Depois tivemos de enfrentar o olhar branco. Um peso inusitado nos oprimiu. O mundo verdadeiro invadia o nosso pedaço. No mundo branco, o homem de cor encontra dificuldades na elaboração de seu esquema corporal. O conhecimento do corpo é unicamente uma atividade de negação. É um conhecimento em terceira pessoa. Em torno do corpo reina uma atmosfera densa de incertezas (FANON, 2008, p. 104)

Muito oportunamente, Fanon (2008) propõe, em sua experiência vivida, uma crítica ao processo de autorrepresentação do negro na luta afrodiaspórica. O autor está radicalmente dizendo que muitas vezes o negro ignora o momento em que sua inferioridade é construída alheia à sua vontade e passa a tratá-la como implícita de si. Os movimentos pan-africacanistas e de libertação africana, para ilustrar, muitas vezes reverenciaram movimentos como Black is beautiful ("O negro é bonito") que traziam consigo os pressupostos do racismo, que dizem o contrário. Seria como se o racismo inculcasse no colonizado negro que o problema com sua identidade é só dele, obrigando-o a se contradizer ao reafirmar as vozes racistas como pressuposto ("não, negro não é bonito"). Guerreiro Ramos (1954), parecendo revoltado contra a tendência sociológica de objetificar o negro (SANTOS, 2017) na literatura de ciências sociais no país, prega com muita força contra essa tendência ao marcar a brancura como lócus de produção do racismo, chamando o racismo de uma patologia do branco brasileiro. É precisamente nesse momento que passamos a delimitar o conceito de lócus de enunciação.

Tal como grafado na teoria de Mignolo (2000), nós compreendemos lócus de enunciação pelo pensar fronteiriço. Isso porque ambos pensamos a partir do Sul global racializado, onde quanto mais escuro se é mais se é racializado, em que racialização significa morte física e de sua memória ancestral. A morte física é o extermínio que presenciamos no país diariamente, em que um jovem negro é assassinado a cada 23 minutos. A morte da memória ancestral é o extermínio por apagamento ou assimilação dos valores e saberes negros. Pensar fronteiriço criticamente é compreender, na mesma inspiração da intelectual chicana Glória Anzaldúa, de que a fronteira não é um lugar de escolha para todos. Como racializados somos empurrados para uma fronteira da modernidade que nos marca ou como não-modernos ou como pré-modernos, não nos deixando critérios de plena escolha.

Raça, portanto, não é uma escolha. À luz de uma fantasia política, raça se configura tão logo como uma tatuagem do horror, um signo perverso, uma fantasia política. Fanon (2008), teorizando nessas margens históricas, chamou de zona do não-ser um lócus habitado pelos racializados. Unindo as peças desse enorme quebra-cabeças, os brancos são aqueles que ocupam a zona da existência, que é a zona do ser. São aqueles que são. Os brancos são, assim, os humanos. Em contradição, os racializados, isto é, em nosso caso, os povos negros, são os não humanizados, os não-humanos, os que não são, aqueles que habitam essa zona do não-ser. Assim, a linha tênue que limita e divide essas duas zonas é um espaço de transição e co-existência negra nesse pensar fronteiriço crítico.

As raízes do lócus de enunciação nos levam, portanto, a confirmar a existência não de um lugar como completo ou bem resolvido, mas de um continuum tanto de suposta estabilidade para os que habitam a zona do ser como de perversão e horror, mas também resistência a essas marcas, do ponto de vista daqueles que ocupam a zona do não-ser.

\section{II}

Nossas notas até aqui têm demonstrado que ambas as teorizações têm abundantes similaridades. Para que então destacar o que é parecido se o que parece que estamos tentando fazer aqui é justamente o contrário, ao pronunciar a importância da heterogeneidade teórica e da infidelidade total a uma dada teoria?

Um exemplo inicial. Somos, pois, homens racializados. Mas homens. Não machos. Esse termo, que traz gatilhos do sistema escravocrata, já impeliu a homens racializados, sobretudo os homens negros brasileiros, a função de macho

5. A patologia do branco brasileiro é, para Guerreiro Ramos, o racismo. Sendo uma patologia do branco, essa metáfora aponta que o branco é o responsável por se livrar do próprio adoecimento, sendo que o racismo e seu fim é sua responsabilidade. 
reprodutor. Os cisheteropatriarcado, muito a serviço desse sistema, o incorporou e, embora esse termo apareça convincente para falar de homens negros, ele traz consigo sua coloração racista. O mesmo faz com que brancos mestiços como Caetano Veloso, não se enxergando no limbo mal resolvido da brancura, e não tendo elementos suficientes para ser lido socialmente como um negro, traga com força em si a categoria de "mulato":

\section{Branquinha}

Eu sou apenas um velho baiano

Um fulano, um caetano, um mano qualquer

Vou contra a via, canto contra a melodia

Nado contra a maré

Que é que tu vê, que é que tu quer,

Tu que é tão rainha?

Branquinha

Carioca de luz própria, luz

Só minha

Quando todos os seus rosas nus

Todinha

Carnação da canção que compus

Quem conduz

Vem, seduz

Este mulato franzino, menino

Destino de nunca ser homem, não

Este macaco complexo

Este sexo equívoco

Este mico-leão

Namorando a lua e repetindo:

A lua é minha

Branquinha

Pororoquinha, guerreiro é

Rainha

De janeiro, do Rio, do onde é

Sozinha

Mão no leme, pé no furacão

Meu irmão

Neste mundo vão

Branquinha

Pororoquinha, guerreiro é

Rainha

De janeiro, do Rio, do onde é

Sozinha

Mão no leme, pé no carnaval

Meu igual

Neste mundo mau.

Nossos grifos acima permitem identificar em que momento o autor, usando o seu eu lírico, se marca como "este mulato franzino", retomando uma palavra que o racialismo à brasileira importou de "mula" para expor o cruzamento mal resolvido da miscigenação que, para alguns estudiosos, representou uma possibilidade de limpeza total do povo preto no país e, para outros, representava a degeneração da raça (OLIVEIRA e OLIVEIRA, 1974; MUNANGA, 2004). Quem usa macho e mulato parece ignorar, portanto, as vozes racialistas de Raimundo Nina Rodrigues, Monteiro Lobato, Euclides da Cunha e Silvio Romero. Por outro lado, esse debate, que reposiciona a heterogeneidade, não 
pode ignorar que somos entrecortados por posições de gênero ligadas às formatações políticas do que é ser homem e do que se espera de um homem no ocidente.

Por outro lado, nossas configurações de racialização, ao sermos lidos como negros aqui no Brasil ou no Reino Unido mostram como o branco tentou, ele mesmo, explorar, generalizar e universalizar a categoria de raça. As similaridades de ambas as teorizações nos carregam para o centro desse escopo.

Nesse sentido, o lócus de enunciação posiciona como nossas experiências vividas nos levam a nos filiar a genealogias que formam o projeto ontológico do que somos. Homens negros (black para a visão limitada do branco racialista que é mal resolvido com sua brancura), mas de diversas formações étnicas, somos homens falando de um sul racializado. Apresentando a defesa dos estudos coloniais e pós-coloniais como lócus de enunciação, Mignolo (1993, p. 129) destaca que:

[...] Minha preocupação é enfatizar a ideia de que o "discurso colonial e pós-colonial" não é apenas um novo campo de estudo ou uma mina de ouro para a extração de novas riquezas, mas condição para a possibilidade de se construírem novos loci de enunciação para a reflexão de que o "conhecimento e compreensão" acadêmicos devem ser complementados pelo "aprender com aqueles que vivem e refletem a partir de legados coloniais e pós-coloniais, Rigoberta Menchú a Angel Rama. Do contrário, corremos o risco de estimular a macaqueação, a exportação de teorias, o colonialismo (cultural) interno, em vez de promover novas formas de crítica cultural de emancipação cultural e política.

Ou seja, como fica evidente na fala de Mignolo (1993), é possível recuperar o debate de lugar de fala pelo debate de lócus de enunciação porque, ao defender a questão pós-colonial mais do que uma área, mas como um lócus onde se dá a enunciação, o estudioso precisa a importância de se ouvir as vozes que já falam naquele lugar e que, portanto, têm seu lugar de fala e lócus de enunciação a serem levados em conta. A fala, que vai ser levada em conta, pode produzir novos lócus de enunciação. ${ }^{6}$ Assim, adicionamos também que, se analisado, o lócus de enunciação também pode levar ao surgimento de novos lugares de fala, inclusive daqueles racializados.

O lugar de fala nos implica recuperar sempre lugar e fala como espaço não acabado de sentido, mas também como espaço em que, longe de ser esvaziado, vai acondicionando sentidos ligados às formas possíveis de existência. Assim, como destaca Ribeiro (2017, p. 36):

Quando falamos de direito à existência digna, à voz, estamos falando de locus social, de como esse lugar imposto dificulta a possibilidade de transcendência. Absolutamente não tem a ver com uma visão essencialista de que somente o negro pode falar sobre racismo, por exemplo.

Ou seja, o que a autora está destacando é justamente como essa fala sempre preenche o lugar com ontologia, isto é, com a experiência vivida de cada sujeito. É precisamente na sujeição ontológica, mas também no movimento ontológico de resistência, que ambas as teorizações se encontram.

Tanto para falar de lugar de fala quanto para discernir suas bases do que é lócus de enunciação será necessário retomar o corpo vilipendiado, sequestrado e levado para longe, ainda que muitas vezes metafisicamente, pela colonialidade (DE SOUZA, 2019). Isto é, será necessário recuperar as marcas desse corpo e sua formatação para não continuarmos usando um vasto repertório racista, como já alertamos anteriormente.

Trazer o corpo de volta, como elemento que destacaremos nas conclusões deste texto, tem a ver com recuperar o elo de ligação entre as duas teorizações, a ontologia perdida. Assim, é possível enunciar essas ontologias, inclusive, nas filiações teóricas de cada um dos conceitos. Por isso, antes mesmo de perfazer o quão essas similaridades podem servir para uma união ou unidade teórica, não sendo esse nosso objetivo, vamos ponderar a seguir algumas diferenças.

As diferenças entre essas teorias têm a ver com dor e direito. As duas evocam diferentemente as vozes de dor e direito em suas ontologias que, perdidas, buscam recuperar a possibilidade de existência.

O lugar de fala, no entanto, não diverge de lócus de enunciação apenas no conteúdo dessas dores. Lugar e fala, embora lugares não acabados, são vistos realmente pelo senso comum como acabados. Embora o esforço da própria autora em seu livro, a discussão dos brancos no país, ao utilizar o livro para se desresponsabilizar pelo racismo

6. Como tem sido repetido desde o início, não estamos aplicando na escrita alfabética de lócus de enunciação para a desinência de plural porque essa palavra não é de língua estrangeira, o latim, mas um empréstimo linguístico em plena execução representada graficamente na escrita em língua portuguesa no Brasil. 
é prova evidente disso. Assim, ao serem perguntados sobre questões girando em torno de racismo, essas pessoas de pronto já anunciam que "esse não é meu lugar de fala".

De fato, ao contrário de enunciação, a fala parece ocupar o último gesto que finaliza o processo de produção desse ato, com a composição histórica dos diversos processos históricos que delimitam e condicionam sua existência. O termo fala parece ser problemático para nós porque até aqui fala tem sido confundida com a oralização de uma dada língua/linguagem, que, como no caso de "sotaque", não permite compreender como seus elementos são formados. Se escolhermos o termo bakhtiniano atopara falar de fala, podemos recorrer às palavras de Mikhail Bakhtin em Para uma filosofia do ato responsável:

Este ato é verdadeiramente real (ele participa do Ser- evento único) apenas em sua inteireza. Apenas esse ato inteiro está vivo, existe completa e inescapavelmente - vem a ser, é completado. Ele é um participante real vivo no evento em processo do Ser: ele está em comunhão com a unidade única do Ser em processo (BAKHTIN, 1993, 20). ${ }^{7}$

Ou seja, fala guarda outros sentidos desde Saussure, que vão além da linguagem como estrutura e apresentam o ato linguístico como ato do Ser. Para o fundador da linguística geral, a fala era expressão do indivíduo enquanto língua era uma expressão de um sistema social de signos. Talvez por isso, para os linguistas de maneira geral, fala ainda esteja profundamente ligada ao ato que enuncia toda uma construção de enunciação que lhe é anterior e que dura até aquele momento, pois, como o próprio Saussure rechaçou nos estudos linguísticos realizados até então, era necessário enfrentar um debate do que é língua partindo de seus aspectos sincrônicos.

Bakhtin (1993) reposiciona esse debate, ao desresponsabilizar a linguagem e despojá-la de seu papel eminentemente fundacional assinalado por Saussure. Ao falar que um ato, que é sempre único e não repetível, não funda uma coisa que lhe é anterior. Assim, se cai uma árvore e a linguagem humana não a representou, ela existiu ainda assim.

Então, por que nos é importante resgatar o papel da fala. Chamando-a por vezes de palavra, Bakhtin (1997) a definiu como ideológica por excelência justamente no sentido de recuperar sua carga anterior, por ela representada. Fala ou palavra, estamos falando de uma representação de uma experiência vivida, sempre única e nunca replicável naqueles moldes. Isso não tira o caráter de arena de poder e com coletividades que a linguagem propicia aos sujeitos, mas também não nega o papel da ontologia.

O grande problema em fala como em lugar de fala é justamente por onde se constrói a visão de fala. Ao buscar essa delimitação, Ribeiro (2017) traz o conceito a partir dos estudos da área de comunicação. O enorme problema em relação a esses estudos é justamente a visão fixa de fala em que, como é o caso do trabalho citado por ela, posição e fala parecem sentidos análogos, quando, na verdade, é a posição que ajuda consolidar uma fala, mas não necessariamente o contrário. Como já vimos, o uso da negação de uma declaração racista muitas vezes só ajuda a demarcar a própria declaração como um pressuposto.

Mais do que na forma, lugar de fala tem enorme legitimidade na luta pelo direito de fala. Ao contrário de diversos autores do Norte global que, ao falar de direitos linguísticos (language rights) sempre esbarram nas políticas linguísticas e sua extensa colaboração com a visão de inglês como língua franca, não falando, muitas vezes, plenamente dos direitos de fala como lugares que grupos minorizados fazem independente de língua enquanto sistema linguístico. É o caso de Ribeiro (2017) ao situar fala como um processo roubado das mulheres negras.

Assim, do ponto de vista de nossa interpretação, o lugar de fala se faz com vários lócus de enunciação, nem sempre bem resolvidos e convergentes, e sempre partindo de contingências. No caso de pessoas negras, essa contingência se estabelece na fronteira da zona do ser, fazendo do corpo negro, como anuncia Mbembe (2018), nem sujeito e nem objeto, mas uma terceira posição. Isso o faz sempre ter que reagir àquela significação que é externa originalmente ao seu corpo, que é ser chamado de negro (NASCIMENTO, 2019), mas também estilizá-la e produzir nela significação. Assim, esse sujeito não é um oco e sempre está editando a estrutura do signo como apresentou, em sua teoria do duplo signo negro, Gates Jr. (1988).

Assim, falar de lugar de fala como um lugar de direito de fala pode parecer algo gerado por um lócus de enunciação da branquitude, mas, se conectado a um lócus de enunciação que traz a fala do negro racializado consigo, não se rende a ele. Nesse ínterim, a seguir apresentamos pontos de encontros entre essas duas teorizações.

7. Tradução de Carlos Alberto Faraco e Cristóvão Tezza. 
O ponto de encontro de ambas as teorizações está justamente na experiência vivida, como recuperada do trabalho de Frantz Fanon, já citado (FANON, 2008). Como estamos fazendo até aqui, ressaltar as similaridades e as diferenças pode nos fazer refletir sobre como essas nossas vozes evocam tristezas e dores que são muito heterogêneas. De maneira geral, o mundo universalista criado pelo racismo europeu no mundo moderno consignou uma suposta identidade uniforme e homogênea do racializado como se essa verdade fosse a verdade fora do mundo branco quando, de fato, essa é verdade do mundo branco.

Se formos consolidar a relação de experiência vivida com espaços a se alcançar com a luta política, que enxerga o corpo como corpus ${ }^{8}$, estou necessariamente enxergando o corpo-político (MIGNOLO, 2003), que fala por si só e muitas vezes não é ouvido, em suas narrativas autobiográficas (cf. FERREIRA, 2015) que precisa ser analisado ontoepistemicamente (REZENDE e SILVA, 2018).

De fato, quando Lorenso (2010) e Souza e Muniz (2017) usam corpo, isso se dá na perspectiva de recuperar a enunciação negra a partir do que estou chamando de lócus de enunciação, isto é, Isto é, a relação entre alteridade e identidade pela primeira autora e o corpus que não é objeto apenas e tem corpo na pesquisa como as outras duas autoras utilizam,-consiste, portanto, em mais do que falar, como repara Mignolo (2003), mas num corpo-político em que todo ele é dor.

Aqui apropriadamente se encontram as teorizações. Podíamos perceber lugar de fala como a tentativa de fugir desse lugar de dor ao usar a fala, enquanto se foge de uma agenda evolucionária que enxerga psicogenicamente o negro. Fanon (2008), ao recuperar a psicogênese, se irrita contra ambas as leituras ontogênicas e filogênicas que recuperam o negro como um grau atrás do branco na agenda evolucionária humana. Assim, essas leituras cognitivistas mostram o europeu como o humano que, graças à filogenia de sua espécie, evoluiu ontogenicamente enquanto as pessoas negras ainda estão cumprindo um passo anterior nessa agenda evolucionária.

É muito importante defender o lugar de fala, mas sem torná-lo um lugar onde fala não recupera o corpo roubado pela colonialidade. Ou seja, não basta ao branco falar de racismo quando pessoas negras permanecem fora de qualquer diálogo epistêmico. Os brancos, por exemplo, ao tentarem usar o lugar de fala como guia, muitas vezes esquecem que não basta se dizer branco, pois exatamente aí, no campo da linguagem, não se produz mudança apenas no resultado, isto é, no enunciado ou fala.

Voltemos à própria origem desses debates na Linguística. Um dos avanços fundamentais na teoria pósestruturalista é justamente o deslocamento do papel da linguagem como acabado para um processo de produção de coisas que, embora já existissem, passam a existir de novo na linguagem. O ponto que merece reflexão é justamente a problematização da linguagem como lugar epistêmico que se basta, como se, para resolver a concentração fundiária brasileira, bastasse apoiar verbalmente a reforma agrária. Mais do que isso, o branco é exemplo recorrente na luta antirracista. Desde o empréstimo de contas em suas redes sociais para pessoas negras até o convite de pessoas negras para agendas específicas em empresas privadas que não fazem uma agenda antirracista na prática, com seus privilégios de só contratar pessoas brancas para os cargos altos. A figura abaixo é um bom exemplo disso. Nela um famoso youtuber cobra o jogador brasileiro Neymar a se posicionar contra o racismo:

8. Eu uso, sobretudo, essa análise a partir de Souza e Muniz, 2017. 
Mas nem todo mundo se importa.

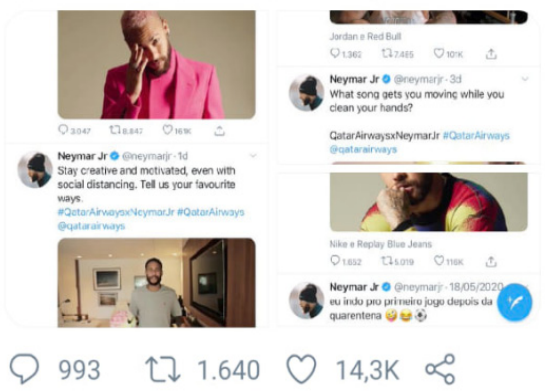

Figura 1. Print da conta de Twitter do youtuber Felipe Neto

Felipe Neto se tornou famoso pelos ataques que fazia nas redes sociais às gestões de Dilma Rousseff. Na época, apesar de muito criticado, apoiou o golpe parlamentar ${ }^{9}$ contra Dilma. Após a vitória do presidente Bolsonaro, não só se tornou um defensor contumaz da democracia, como do próprio antirracismo. No print da Figura 1, ele não só cobra uma postura de Neymar, mas ironiza o fato do jogador seguir sua vida enquanto há manifestações antirracistas pelo mundo. Neymar, que já disse que não se considera negro, ${ }^{10}$ está, portanto, sendo cobrado por um homem insuspeitamente branco sobre seu posicionamento. Dentro do grande limbo que é o mestiço brasileiro (OLIVEIRA e OLIVEIRA, 1974), Neymar não precisa se dizer negro para estar imerso em lócus de enunciação negros, mesmo sendo insuspeitamente mestiço, quando assim o branco o quer.

Ou seja, mesmo não se dizendo negro, tanto o branco racista tradicional quanto o progressista racista o querem negro e o veem negro, assumindo um peso que ele não necessariamente tem que assumir do ponto de vista de uma linha evolucionária (FANON, 2008, ao questionar essa vinculação direta de negro preso a esse sistema escravocrata, faz ponderações parecidas). Neymar é, assim, duplamente racializado pelo branco, tanto conservador quanto progressista, que o quer negro.

Aqui não defendo que Neymar não precisa se posicionar. Sempre e quando quiser, isso será importante. No entanto, não é Neymar o ponto de análise, mas o branco que o cobra. Imerso em sua branquitude, ele não percebe estar falando com um homem que foi dissociado, pelo próprio racismo e racialização, de suas origens raciais. Não é genótipo que o liga aos seus antepassados negros, porque os negros brasileiros vão perdendo pouco a pouco as suas ligações genotípicas, mas fenótipo.

Mais do que isso, o youtuber está apenas usando lugar de fala sem algum vínculo com lócus de enunciação. Trata-se, assim, da responsabilização da linguagem como ato final, sem se perceber que a linguagem é o que funda o ato desde o começo, mesmo quando o branco ainda não se preocupava com questões raciais, enquanto racializava com sua própria existência em seus lócus de enunciação privilegiado.

O ponto de encontro de ambas as teorizações aqui discutidas está justamente em recuperar os elos perdidos entre elas, responsabilizando mais o lócus de enunciação do que o lugar de fala.

A seguir acrescento, como palavras conclusivas, mais dois aspectos que permitem reunir e conclamar a existência desse elo perdido.

Concluímos, inicialmente, que as teorias não precisam convergir. Pelo contrário, é em sua divergência que elas de fato funcionam. Mas elas podem se encontrar. Por isso, para finalizar este texto eu reúno justamente o elo que

9. Seguindo a linha de vários linguistas, como Possenti (2018), também chamo o impeachment contra a presidenta Dilma de um golpe parlamentar. Nesse caso, entendo que não houve o crime de responsabilidade fiscal com o qual foi acusada por não terem sido provados à época os elementos que configuram relação do tesouro com bancos públicos como pedaladas, e nem que pedaladas assumem o lugar de crime de responsabilidade, já que se trata de um mecanismo cuja presença não expressa na legislação depõe nulidade ao processo. Isso, por si só, constitui um argumento que desconstrói a visão de impeachment por crime de responsabilidade. Os motivos do golpe foram muitos. O mais presente deles no discurso dos parlamentares era justamente a irritação do mercado com o déficit público, este oriundo dos altos investimentos do Estado em políticas públicas à época.

10. Veja mais em <http://globoesporte.globo.com/platb/marvio-dos-anjos/2014/05/01/neymar-nao-se-acha-negro-canalhice-ou-desinformacao/> 
considero perdido nessa relação, que é como trazer o corpo de volta (DE SOUZA, 2019)e marcar o não-marcado (MENEZES DE SOUZA, 2018).

Trazer o corpo de volta é exatamente uma pronúncia do que fazer com o corpo-político ferido. De Souza (2019) propõe que essa é uma tarefa crucial ao pensamento decolonial:

O fato é que, quando falamos sobre discurso na academia, e aqui estou eu usando a teoria decolonial, é importante trazer nossos corpos de volta. Uma das críticas que a decolonialidade faz é que na criação da universalidade e da modernidade que, segundo a teoria decolonial, começou com o contato colonial entre a Europa e os americanos - quando os ibéricos tiveram o primeiro contato com os ameríndios - só trouxeram com eles o que eles sabiam. Quando viram os ameríndios, tudo que viram foi deficiência, ausência, ignorância, o que concluíram ser traços de primitivos. Esse contato, que criou o 'outro' como primitivo, foi o que estabeleceu a modernidade dos europeus e ibéricos (DE SOUZA, 2019, p. 10).

Assim, trazer o corpo de volta tem a ver com recuperar a experiência de existência que tem sido sequestrada consistentemente pela colonialidade até os dias atuais. A ausência de sobrenomes africanos, por exemplo, é um dos casos mais nítidos de como a linguagem está inserida nessa experiência. Ao contrário de brancos, e até de mestiços com ascendência direta da Europa, pessoas negras normalmente não conhecem a proveniência de seus sobrenomes africanos, porque simplesmente muitas vezes têm sobrenomes de batismo, como é o caso do meu, Nascimento dos Santos. Os brancos, ao contrário, não só conseguem gozar das origens europeias de seus nomes, como o fazem sem refletir como essa posição reflete seus privilégios raciais não-marcados, como se pode perceber na imagem a seguir, retirada de um perfil no Facebook:

\title{
SOU DESCENDENTE DE PEDRO ÁLVARES CABRAL
}

\begin{abstract}
Eis que ontem, descubro que Pedro Álvares Cabral, aquele cara que se perdeu na viagem às Índias e "descobriu" o Brasil em 1500, é meu $16^{\circ}$ avô! Com base nas análises documentais, de registros e dos fatos dele e de seus descendentes, dá par... Ver mais
\end{abstract}

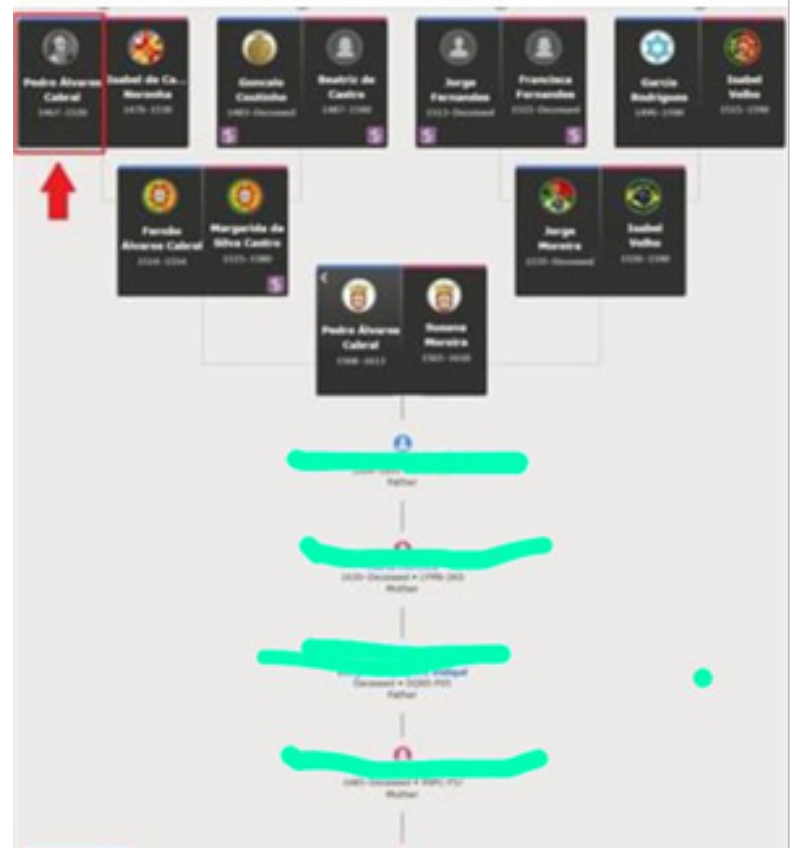

Figura 2. Print de perfil de Facebook

O print foi retirado do perfil de um conhecido de Curitiba que, já há algum tempo, tem desbravado a sua linhagem genealógica. Desde que ele começou essa guinada, e por eu ser homem negro mestiço, eu tive que excluir seu perfil para não sofrer tanto. Eis que nesse último post ele se diz descendente direto justamente de um dos mais cruéis invasores do mundo ocidental, Pedro Álvares Cabral. 
Isso mostra que, ao contrário dos brancos, não temos o privilégio de refazer a narrativa das origens dos nossos sobrenomes africanos. Trazer o corpo de volta permite, assim, não apenas recompor um sobrenome, mas recompor a necessidade de agir politicamente com o corpo contra as narrativas racistas que nos aprisionam.

Por outro lado, se é preciso trazer o corpo de volta, isso não se dará sem marcar o não-marcado, como é o caso do privilégio branco não marcado na figura. Isto é, sem marcar o lócus de enunciação que permanece pressuposto, mas que deve passar ao mundo do posto. Menezes de Souza (2018), por exemplo, ao falar de epistemologias do sul a partir dos povos indígenas, experimenta narrar cada contribuição teórica apontando a qual lócus de enunciação ela se relaciona ou pertence. Assim, "marcar o não marcado e mudar os termos hegemônicos da conversa é a estratégia de reconstituição epistêmica que vários pensadores latino-americanos propõem dentro do guarda-chuva de conceitos como decolonialidade e colonialidade" (SOUZA, 2018, p. 3).

Marcar o não-marcado, assim, assume o fim deste texto como uma forma de marcar não só a branquitude não-marcada, mas as experiências de corpo-político sequestrado que foram destruídas e que precisam ser retomadas. Para este texto marcar o não-marcado é forçar ao corpo branco sempre assumir suas limitações epistêmicas que podem comprometer uma dada análise do texto. Para além disso, o reconhecimento da branquitude como um poder subjacente a qualquer atuação por meio da linguagem.

Tanto lugar de fala quanto lócus de enunciação têm espaçonessa tentativa de trazer o corpo de volta e marcar o não-marcado. Esses elementos são oferecidos, como complementação aos termos defendidos até aqui como necessidade de conversar com ambas as teorias, localizando suas delimitações, similaridades, diferenças e pontos de encontro, sem necessariamente fazê-las convergir por convergir.

\section{REFERÊNCIAS}

ANZALDUA, G. Borderlands: the new mestiza = La frontera. San Francisco : Aunt. Lute, 1987.

BAKHTIN, M. M. (Mikhail Mikhailovich). Marxismo e filosofia da linguagem: Problemas fundamentais do método sociologico na ciencia da linguagem. 8.ed. São Paulo; Hucitec, 1997.

BAKHTIN, M. Toward a Pbilosopby of the Act. Austin: University of Texas Press, 1993.

BENVENISTE, É. Problemas de lingüística geral. São Paulo, SP: Companhia Editora Nacional, 1976.

CRENSHAW, K. Demarginalizing the Intersection of Race and Sex: A Black Feminist Critique of Antidiscrimination Doctrine, Feminist Theory and Antiracist Politics. University of Chicago Legal Forum, n.1, 1989.

DAVIS, A. Women, race and class. Nova Iorque: First Vintage Books Edition, 1983.

DE SOUZA, L. M. T. M. Decolonial pedagogies, multilingualism and literacies. Multilingualism and Literacies. Multilingual Margins: A journal of multilingualism from the periphery, v. 6, p. 1-15, 2019.

FANON, F. Pele Negra Mascaras Brancas. Salvador: EdUFBA, 2008.

FERREIRA, A. J. Narrativas Autobiográficas de Identidades Sociais de Raça, Gênero, Sexualidade e Classe em Estudos da Linguagem. 1. ed. Campinas: Pontes Editores, 2015. v. 1. 288p

FOUCAULT, M.. A arqueologia do saber. 7. ed. Rio de Janeiro: Forense Universitária, 2009.

GATES JR., H.L. The Signifying Monkey: a Theory of African-American Literary Criticism, Oxford University Press, 1988.

GUERREIRO RAMOS, A. O problema do negro na sociologia brasileira. Cadernos do Nosso Tempo, 2, jan./jun, 1954.

HILL COLLINS, P. Black Feminist Thought: Knowledge, Consciousness, and the Politics of Empowerment. Boston :Unwin Hyman, 1990.

LADSON-BILLINGS, G.; TATE, W. Toward a Critical Race Theory of Education. Teachers College Record. 97. 47-68, 1995. 
LORENSO, S. (2010). Entre silêncios e ditos: Estilos de enunciação negra na perspectiva semiótica. In: E. Almeida Pereira (Org.) Um tigre na floresta de signos: Estudos sobre poesias e demandas sociais no Brasil. Belo Horizonte: Mazza Edições, 2010.

MAKONI, S.; PENNYCOOK, A. Disinventing and Reconstituting Languages. In: MAKONI, S.; PENNYCOOK, A. (Orgs.) Clevedon: Multilingual Matters, 2007.

MAY, S. Language rights and language policy: addressing the gap(s) between principles and practices. Current Issues in Language Planning, 16:4, 355-359, 2015

MBEMBE, A. Necropolítica. São Paulo: N-1 edições, 2018.

MENEZES DE SOUZA, L.T.M. Glocal Languages, Coloniality and Globalization from below. In: GUILHERME, M.; SOUZA, L.M.T. (Orgs.). Glocal languages and Critical Intercultural Awareness. Nova Iorque: Routledge, 2018.

MIGNOLO, W. Colonial and Postcolonial discourse: Cultural critique or academic colonialism? Latin American Research Review, n. 3, p. 120-134, 1993

MIGNOLO, W. Local Histories/Global Designs. Chichester: Princeton University Press, 2000.

MUNANGA, K. Rediscutindo a mestiçagem no Brasil: identidade nacional versus identidade negra. Belo Horizonte: Autêntica, 2004.

NASCIMENTO, G.. Racismo linguístico: os subterrâneos da linguagem e do racismo. 1. ed. Belo Horizonte: Letramento Editorial, 2019.

Oliveira e Oliveira, Eduardo de. O mulato: um obstáculo epistemológico. Argumento, jan. de 1974.

POSSENTI, S. A misoginia como condicionante do golpe de 2016 no Brasil. Discurso \& Sociedad, v. 3, p. 581-593, 2018.

RATO, A.; FLORES, C.; NEVES, D.; OLIVEIRA, D. A competência fonológica de falantes bilingues luso-alemães: um estudo sobre sotaque global, compreensibilidade e inteligibilidade da sua língua de herança. Diacrítica, Braga, v. 29, n. 1, p. 297-326, 2015.

REZENDE, T. F.; SILVA, D. M. Desobediência linguística: por uma epistemologia liminar que rasure a normatividade da língua portuguesa. PORTO DAS LETRAS, v. 4, p. 174-202, 2018.

RIBEIRO, D. O que élugar de fala?Belo Horizonte: Letramento, 2017.

SANTOS, R. O negro objetificado na obra de Caio Prado Jr. e Florestan Fernandes: uma análise das narrativas sóci-históricas na construção do pensamento social brasileiro. Africa e Africanidades,n. 23, 2017.

SINGH, J. Untbinking mastery: dehumanism and decolonial entanglements. Durham : Duke University Press, 2018.

SOUZA, A.L. S; MUNIZ, K. S. Descolonialidade, performance e diáspora africana no interior do brasil: sobre transições identitárias e capilares entre estudantes da UNILAB. L\&S Cadernos de Linguagem e Sociedade, v. 19, p. 80-101, 2017.

SPIVAK, G. C. Subaltern Studies: Deconstructing Historiography. In: SPIVAK, G. C. In Other Worlds: Essays in Cultural Politics. New York: Methuen, 1987.

VERONELLI, G. A coalitional approach to theorizing decolonial communication. Hypatia, 31 (2), 404-420, 2016.

Recebido: 30/10/2020

Aceito: 8/3/2021

Publicado: 22/3/2021 